\title{
Evaluation of determinants influence for consumption of livestock products in second-tier cities of Tamil Nadu in India
}

\author{
Priyadharsini $\mathbf{S}^{1}$, G Kathiravan ${ }^{182 *}$, M Thirunavukkarasu' ${ }^{1}$ and $\mathbf{W}$ Ganpat $^{2}$
}

${ }^{1}$ Tamil Nadu Veterinary and Animal Sciences University, Department of Animal Husbandry Statistics and Computer Applications, Madras Veterinary College, Chennai - 600 007, India; ${ }^{2}$ The University of the West Indies, Faculty of Food and Agriculture, St. Augustine, Trinidad

\begin{abstract}
A study was carried out in two Second-Tier cities of Tamil Nadu, viz., Coimbatore and Salem, with the objectives to analyze the factors influencing the consumption pattern of three major livestock products, namely milk, egg and meat. Multistage sampling procedure was adopted to select 160 household consumers, 80 from each of the cities. Relevant data were collected through personal interview with the help of a pilot-tested interview schedule. Semi-log functional analysis for household consumption of milk revealed that family size, education, region of sample household and dummies for children, income and physical exertion were found to be significantly influencing the consumption of milk. However, egg consumption was influenced by family size, education, food habits, region, presence of children/aged in the household, income levels and physical exertion of family members. Of the independent factors chosen for the model fitted for household meat consumption, family size and dummies for Hindu, region, aged and income categories were found significantly influencing the consumption of meat.As the consumers are segmented by the key quality attributes of livestock products and by socio-economic factors, strategies are necessarily to be evolved and strengthened for enabling niche marketing on identifiable sub-groups.
\end{abstract}

Key words: livestock products consumption, milk, egg, meat, Tamil Nadu, India

Bangladesh Animal Husbandry Association. All rights reserved.

Bang. J. Anim. Sci. 2016. 45 (3): 25-30

\section{Introduction}

The food basket in India is undergoing a significant shift, away from staple food grains toward high-value food commodities, such as fruits, vegetables, milk, meat, eggs and fish. The expenditure share of animal food products in total food expenditure over the past two decades had witnessed a marked increase. Milk and dairy products are a major source of cheap and nutritiousfood to millions of Indians (Ohlan, 2012).Dairy products contributed about 6.4 per cent of calorie intake in rural and 8 per cent in urban India in 2009-10, while their contribution in protein intake was 9 per cent in rural and 13 per cent in urban areas for the same period (NSSO, 2012). The per capita quantity consumption of all the livestock products showed an increase in both rural and urban households. The quantity consumption of chickenincreased by $208.89 \%$ followed by pork (36.36\%), beef(21.84\%) and mutton (9.40\%). Next to chicken, the per capita quantity consumption of egg almost doubled (87.23\%) and milk and milk products by $8.69 \%$ in $2011-12$ as compared with 2004-05 (Chengappaet al., 2016). As income rises, the poor also tend to include more of highvalue food products in their food basket. The changes in consumption pattern were driven by sustained rise in per capita income, urbanization, changing lifestyles, increasing number of women in the workforce, nuclearization of families, improvements in transport infrastructure, rise of supermarkets and increasing use of credit cards (Pingali and Khwaja, 2004). These trends are quite robust and are expected to continue in the near future, implying a vigorous growth in demand for livestock products (Ravi and Roy, 2006; Kumar et al., 2007).

Urbanizationis closely linked to the economic activities and consequent developments in both production and consumption of a particular area. Tamil Nadu ranks first in urbanization among the fifteen major States of the country.In the last 20 years, the rate of urbanization in Tamil Nadu has been rapid. According to the 1991 Census, only

\section{*Correspondingauthor:Kathiravan.Gopalan@sta.uwi.edu}




\section{Consumption of livestock products at Tamil Nadu}

34.15 per cent of the total population in Tamil Nadu was classified as urban but in 2011 , it has risen to 48.45 per cent, an increase of 14.3 per cent. Since the 2001 census, the percentage of urban population has risen by 4.41 per cent (Sivakumar, 2011).Even spread of small, medium and major towns, migration of people from rural areas in search of employment and the presence of industrial estates in all districts contributed to speedy urbanization of Tamil Nadu (The Hindu, 2015).The demand for livestock products in Tamil Nadu has also undergone a perceptible change in the recent past, reflecting the growth in per capita income, urbanization and their repercussions. With the rapid changes in socio economic environment, it becomes essential to study the factors influencing the consumption pattern of three major livestock products, viz., milk, meat and egg in the Second-Tier cities of Tamil Nadu, where the population is currently increasing due to rapid industrial growth, urbanization and improved infrastructure in all spheres.

\section{Methodology}

Among all, the Second-Tier cities of southern peninsular state of India, the Tamil Nadu were considered as the universe of this study. Among the five Second-Tier cities of Tamil Nadu, two corporation cities, viz., Coimbatore and Salem were selected randomly. Increased industrial growth coupled with rapid urbanization that in turn triggered increasing inhabitations of different income strata are the characteristic features of these two selected corporation cities. The residents of these cities not only had the benefit of urbanization in terms of a variety of consumer products, but also had reaped the advantages of access to fresh livestock products, as the leading livestock production pockets were adjacent to these cities. Of these two cities, Coimbatore is the second largest city of Tamil Nadu, known for its textile and manufacturing factories, engineering firms and automobile parts manufacturers, while Salem is the fifth largest city of the State, sheltering largely cottage industries. It also houses a number of industries including Steel Authority of India Limited (SAIL) and an exclusive Electrical and Electronics Industrial Estate.

A multistage sampling procedure was adopted to select the respondents of the study. In the first stage, as stated above, two Second-Tier cities, viz. Coimbatore and Salem were selected randomly. In the second stage, eight zones, four from each of the two selected cities, were randomly chosen and in the third stage, 16 wards, two from each chosen zone were selected using simple random sampling technique. In the fourth stage, 160 household respondents, 10 from each of the selected wards were chosen randomly. Thus, this study had the sample size of 160 household consumers comprising 80 from each of the cities.From the selected household consumers, relevant data were collected to achieve the objectives of the study. The data were collected through personal interview with the sample respondent households with the help of a structured and pilot-tested interview schedule.

Consumption functions were specified and econometrically estimated in semi-log form using economic theory (Kooreman and Wunderink, 1997). These functions explained how household consumption varies in response to variations in the socio-economic factors. Ordinary least square (OLS) multiple regression models were used to econometrically estimate the function.In order to assess the interrelationships between consumption of livestock products (milk, egg and meat) and the socio-economic and psychological factors, as described by Daisyrani (1995), three Semi-log functions, one each for milk, meat and eggs, were fitted. The functional forms were as below:

$$
\begin{aligned}
& \ln Y_{1}=\alpha+\beta_{1} X_{1}+\beta_{2} X_{2}+\beta_{3} X_{3}+\beta_{4} X_{4}+\beta_{5} X_{5}+\beta_{6} X_{6}+\beta_{7} X_{7}+\beta_{8} X_{8}+\beta_{9} X_{9}+\beta_{10} X_{10}+\beta_{11} X_{11}+\varepsilon \\
& \ln Y_{2}=\alpha+\beta_{1} X_{1}+\beta_{2} X_{2}+\beta_{3} X_{3}+\beta_{4} X_{4}+\beta_{5} X_{5}+\beta_{6} X_{6}+\beta_{7} X_{7}+\beta_{8} X_{8}+\beta_{9} X_{9}+\beta_{10} X_{10}+\beta_{11} X_{11}+\varepsilon \\
& \ln Y_{3}=\alpha+\beta_{1} X_{1}+\beta_{2} X_{2}+\beta_{3} X_{3}+\beta_{4} X_{4}+\beta_{6} X_{6}+\beta_{7} X_{7}+\beta_{8} X_{8}+\beta_{9} X_{9}+\beta_{10} X_{10}+\beta_{11} X_{11}+\varepsilon
\end{aligned}
$$

Where, 


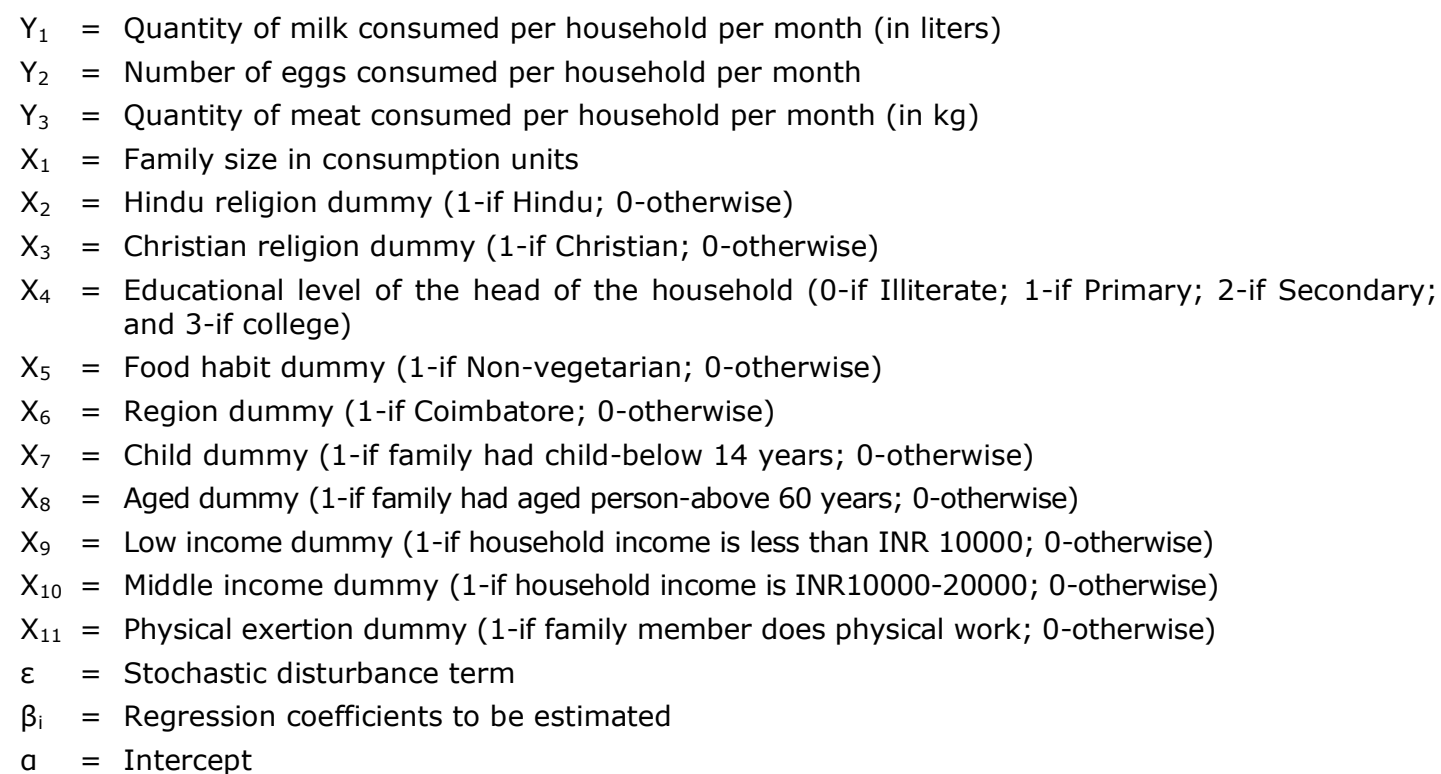

\section{Results and Discussion}

Three semi-log regression functions were fitted separately for milk, egg and meat to examine if the differences in consumption pattern of livestock products could be attributed to variations in the socio-economic factors such as family size, income, religion, education, age, level of physical activity and food habit. The models were tested for violations of OLS assumptions and found they were free from them. Table 1 presents the results of the semi-log functions fitted.

\section{Factors influencing the consumption of milk}

Of the variables used to explain the variation in the consumption of milk in Second-Tier cities of Tamil Nadu, family size, education, region of sample household (viz., Coimbatore and Salem) and dummies for children, income (low and middle income groups) and physical exertion were found to be significantly influencing the consumption of milk. The model showed a good fit with the adjusted $R^{2}$ of 0.707 , indicating that 70.70 per cent of variation in the dependent variable was explained by the independent variables incorporated. The ANOVA also exhibited that the model had a good fit with a significant ' $F$ ' value of 35.908 .
The results indicated that a unit change in the family size could alter the monthly household consumption of milk by 8.90 per cent from its mean level. Similarly, the educational level increased consumption of milk increased by 2.90 per cent. If the consumer happened to reside in CoimbatoreCity, his/her consumption might increase by 11.70 per cent over his/her counterpart in SalemCity, which might be attributed to the relative cold weather of Coimbatore. The per cent variation in the household milk consumption as a result of having a child in the family was estimated to be 6.0 . Among the income categories, the consumption level in the low income group was significantly lower by 13.50 per cent against the other two income categories. As the status of the household moved to middle income group, its chances of drinking milk increased by 13.90 per cent, which confirms the income-elastic demand for milk products. Similar results were reported by Prabaharan and Patel (1983), Ratnam (1984), Goswami (1994), Daisyrani (1995), Inamkeet al. (1995) and Senthilkumar (2003). Also, these results are in tandem with the report of the Department of Animal Husbandry Economics (2003). As expected, the household doing higher levels of physical activity increased its 
consumption of milk by 3.40 per cent to replenish its nutritional requirements.

\section{Factors influencing the consumption of egg}

The semi-log functional model constructed to explain the factors influencing the household consumption of eggs was also a good fit with an adjusted $R^{2}$ of 0.724 . The ANOVA, with a significant ' $F$ ' value of 34.927 , also supported the good fit of the functional model. Of the explanatory variables included, family size, education, food habits (viz., vegetarian and nonvegetarian) and dummies for region, children, aged, low-income category and physical exertion were all found to be significantly determining the consumption of egg.

Table 1. Factors influencing the consumption of livestock products

\begin{tabular}{|c|c|c|c|}
\hline \multirow{2}{*}{ Explanatory factors } & \multicolumn{3}{|c|}{ Explained variables } \\
\hline & Milk & Egg & Meat \\
\hline (Constant) & $\begin{array}{l}3.000 * * * \\
(0.064)\end{array}$ & $\begin{array}{l}1.335 * * * \\
(0.165)\end{array}$ & $\begin{array}{l}1.045^{* * *} \\
(0.190)\end{array}$ \\
\hline Family size & $\begin{array}{l}0.089 * * * \\
(0.010)\end{array}$ & $\begin{array}{l}0.165^{* * *} \\
(0.019)\end{array}$ & $\begin{array}{l}0.373 * * * \\
(0.033)\end{array}$ \\
\hline Hindu & $\begin{array}{l}0.113 \\
(0.034)\end{array}$ & $\begin{array}{l}0.015 \\
(0.061)\end{array}$ & $\begin{array}{l}-0.106^{*} \\
(0.103)\end{array}$ \\
\hline Christian & $\begin{array}{l}0.065 \\
(0.047)\end{array}$ & $\begin{array}{l}0.198 \\
(0.086)\end{array}$ & $\begin{array}{l}0.360 \\
(0.144)\end{array}$ \\
\hline Education & $\begin{array}{l}0.029 * * * \\
(0.010)\end{array}$ & $\begin{array}{l}0.048 * * \\
(0.020)\end{array}$ & $\begin{array}{l}0.024 \\
(0.033)\end{array}$ \\
\hline Food habit & $\begin{array}{l}-0.008 \\
(0.027)\end{array}$ & $\begin{array}{l}0.505^{* * *} \\
(0.116)\end{array}$ & $\cdots$ \\
\hline Region & $\begin{array}{l}0.117 * * * \\
(0.017)\end{array}$ & $\begin{array}{l}0.162 * * * \\
(0.034)\end{array}$ & $\begin{array}{l}0.105^{*} \\
(0.057)\end{array}$ \\
\hline Child & $\begin{array}{l}0.060 * * * \\
(0.018)\end{array}$ & $\begin{array}{l}0.130 * * * \\
(0.034)\end{array}$ & $\begin{array}{l}0.005 \\
(0.057)\end{array}$ \\
\hline Aged & $\begin{array}{l}-0.023 \\
(0.023)\end{array}$ & $\begin{array}{l}-0.207 * * * \\
(0.044)\end{array}$ & $\begin{array}{l}-0.165 * * \\
(0.074)\end{array}$ \\
\hline Low income & $\begin{array}{l}-0.135^{* * *} \\
(0.025)\end{array}$ & $\begin{array}{l}-0.340 * * * \\
(0.048)\end{array}$ & $\begin{array}{l}-0.515 * * * \\
(0.082)\end{array}$ \\
\hline Middle income & $\begin{array}{l}0.139 * * * \\
(0.026)\end{array}$ & $\begin{array}{l}0.022 \\
(0.048)\end{array}$ & $\begin{array}{l}-0.448 * * * \\
(0.081)\end{array}$ \\
\hline Physical exertion & $\begin{array}{l}0.034^{*} \\
(0.017)\end{array}$ & $\begin{array}{l}0.102 * * * \\
(0.033)\end{array}$ & $\begin{array}{l}-0.023 \\
(0.057)\end{array}$ \\
\hline $\mathrm{R}^{2}$ & 0.727 & 0.746 & 0.681 \\
\hline Adjusted $\mathrm{R}^{2}$ & 0.707 & 0.724 & 0.656 \\
\hline 'F' value & $35.908 * * *$ & $34.927 * * *$ & $27.513 * * *$ \\
\hline $\mathrm{N}$ & 160 & 144 & 140 \\
\hline
\end{tabular}

Figures in parentheses indicate standard errors. ... Independent variable, foodhabbit $\left(\mathrm{X}_{5}\right)$ was not included in the model as non-vegetarianswerealoneconsidered for ananlysingdependant variable, meat.* Significant $(\mathrm{P} \leq$ $0.10)$; ** Significant $(\mathrm{P} \leq 0.05)$; *** Significant $(\mathrm{P} \leq 0.01)$. 
The per cent increase in the monthly household consumption of egg for a unit increase in the size of the family was ascertained to be 16.5. As the education level increased, the household consumption was increased by 4.8 per cent, which could be attributed to their better knowledge on nutritional qualities of egg. Selvaraj (1996) also reported similar findings in his study at ChennaiCity. However, in contrast to the findings of Daisyrani (1995), the results of this study revealed that non-vegetarians consumed 50.5 per cent more eggs over their vegetarian counterparts. Similar to the case of milk, the households of CoimbatoreCity were found to be consuming 16.2 per cent more eggs than the consumers of Salem households. This could be due to the impact of rapid industrialization and urbanization and its associated aftermath like increased percapita income and change in food habits induced by the altered lifestyle along with the abundant fast food retail outlets. The significance of the dummy variable for child in the household exhibited that it was boosting the monthly household consumption by 13.0 per cent, which could be attributed to the fact that the households having children were aware of healthy feeding to meet up their nutritional requirements. In contrast, the dummy included for the aged in the household was found to be dragging down the egg consumption by 20.7 per cent, as adults are calorie conscious. The monthly household egg consumption level of lower income category was 34.0 per cent lesser than that of middle and higher income groups. Akin to milk consumption model, the function fitted for egg revealed that the households performing a higher physical activity increased their egg consumption by 10.2 per cent to compensate the burnt-out calories. Although the results of this study are in accordance with reported findings of the Department of Animal Husbandry Economics (2003), the results, however, varied from the findings of Daisyrani (1995), who reported that only income and the Hindu religion dummy were significantly influencing the egg consumption.

\section{Factors influencing the consumption of meat}

Of the independent factors chosen for the model fitted for household meat consumption, family size and dummies for Hindu, region, aged and income categories were found significantly influencing the consumption. The adjusted $R^{2}$ value was 0.656 , which reflected that 65.60 per cent of variation in meat consumption was due to the variables included in the model. The ANOVA also indicated that the model had a good fit with a significant $F$ value of 27.513 .

It could be noted that a unit increase in the family size could increase the household consumption of meat by 37.30 per cent from its mean level. The religion dummy-Hindu was negatively influencing the meat consumption by 10.60 per cent vis-à-vis Christians and Muslims due to the obvious religious customs and meat holidays. Here again, the consumers in CoimbatoreCity were consuming 10.50 per cent more meat than the consumers in SalemCity. The explanatory variable denoting aged (more than 60 years), as expected, had a significant negative influence on the quantity of meat consumed to an extent of 16.50 per cent. As people got older, they either restricted or discontinued the consumption of meat for health reasons. The results showed that the lower and middle income groups were consuming lesser quantity of meat as compared to higher income group to the tune of 51.50 and 44.80 per cent, respectively, possibly due to the financial constraints and escalating meat prices. Similar results were reported by Reddy et al. (1984) and Daisyrani (1995) in their studies in ChennaiCity.

\section{Conclusion}

Consumption of livestock products per consumption unit showed an increasing trend with increase in household income as livestock products are still luxurious in the country, which continue to have income elastic demand. Hence, the future demand for livestock products can be predicted to be high especially in developing countries like India, where per capita income is on the rise constantly. This imparts the need for enhancing the production of quality livestock products, together by developing a well- 
organized distribution system. As the consumers are segmented by the key quality attributes of livestock products and by socio-economic factors, strategies are necessarily to be evolved and strengthened for enabling niche marketing on identifiable sub-groups. The livestock production and marketing approaches should take into account the various determinants of consumer demand such as preferences, choices and sentiments that influence the consumption behavior of households, while popularizing species specific farming.

\section{References}

ChengappaPG, M Umanath, K Vijayasarathy, PradeepaBabuand AV Manjunatha (2016). Changing demand for livestock food products: An evidence from Indian households. Indian Journal of Animal Sciences 86 (9): 1055-1060.

Daisyrani MS (1995). Consumption pattern, Consumers' awareness and preferences for selected livestock products. Unpublished M.V.Sc. thesis submitted to TANUVAS, Chennai-600 051.

Department of Animal Husbandry Economics (2003). Report of the 'Study on market structure, conduct and performance of major livestock products (milk \& mutton) in Tamil Nadu', Madras Veterinary College (2003). pp.1-78.

Goswami SN (1994). Differences in the consumption pattern of milk and milk products among different income groups. Indian Journal of Dairy Science, 47(1): 62-64.

Inamke NM, SN Tilekar and DP Kaledhonkar(1995).Milk consumption by households in Western Maharastra.Indian Journal of Dairy Science, 47(6): 34-37.

Kooreman P and SWunderink (1997). The Economics of Household Behavior. Macmillan Press LTD., London. pp.256

Kumar P, Mruthyunjaya andPS Birthal (2007).Changing consumption pattern in South Asia, cited in Joshi, P.K., A. Gulati and R.J. Cummings (Eds.), Agricultural Diversification and Smallholders in South Asia.New Delhi: Academic Foundation.
NSSO (2012). Nutritional Intake in India (Report No. 540 (66/1.0/2)). New Delhi: Department of Statistics, Government of India.

Ohlan R (2012). Global Competitiveness in Dairy Sector', Agricultural Situation in India, 59(5): 21523.

Pingali $P$ and $Y$ Khwaja (2004).Globalization of Indian diets and the transformation of food supply systems.ESA Working Paper No. 04-05, Food and Agriculture Organization, Rome.

Prabaharan R andRK Patel (1983).A study on the consumption pattern of milk and milk products in Madras city.Cheiron, 12: 136-140.

Ratnam C (1984). The effect of education on the consumption of milk: A case study of Visakapatnam. Indian Journal of Dairy Science, 37: 214-216.

Ravi C and D Roy (2006). Consumption patterns and food demand projections: A regional analysis. Paper presented at the workshop, Plate to Plough: Agricultural Diversification and Its Implications for the Smallholders, organized by the IFPRI and the Institute of Economic Growth, New Delhi at New Delhi, September 20-21.

Reddy DS, NR Kosalaraman andR Ramamurthy (1984).Trends in consumption of various meats in Madras city.Cheiron, 6: 203-303.

Selvaraj P (1996). A study on consumption pattern and consumer awareness for egg and its products. Unpublished PGDBM project report submitted to TANUVAS, Chennai-600 051.

Senthilkumar G (2003). Consumption pattern of selected milk products (butter, curd, ghee and ice cream) in Chennai. Unpublished PGDBM project report submitted to TANUVAS, Chennai-600 051.

Sivakumar B (2011). Census 2011: Tamil Nadu 3rd most urbanised state. http://timesofindia.indiatimes.com/ city/chennai/Census-2011-Tamil-Nadu-3rd-mosturbanised-state/articleshow/9292380.cms

The Hindu (2015). What drives urbanization in Tamil Nadu.http://www.thehindu.com/news/national/tamil -nadu/what-drives-urbanisation-in-tamil-nadu/ article7386961.ece 